\title{
Chapter
}

\section{An overview on aquatic biodiversity of India}

\author{
Sunil Kumar1,* and Shoma Devi ${ }^{2}$ \\ ${ }^{1}$ Department of Zoology, D.A.V.(P.G.) College, Dehradun (Uttarakhand), India \\ ${ }^{2}$ Department of Zoology, Krishna College of Science and I.T. Bijnor (Uttar Pradesh), India
}

\begin{abstract}
Globally the actual number of species in world is estimated to be between 10- 30 million species, in which about 2 million species which have been identified. Freshwater ecosystems account for $0.01 \%$ of the earth's surface water but $10 \%$ of species. According to the UN Environment Programme. The study of biodiversity on both global and regional scales come mainly from the terrestrial environment despite the marked distinctive features of marine biodiversity and the fact that the aquatic (freshwater \& marine) environment occupies more than two thirds of the Earth's surface. The highest loss of freshwater biodiversity has been reported from the Indian subcontinent, specifically the Gangetic plains. Reason why the government has taken up the project of biodiversity conservation in the region. Each species is adapted to its unique niche in the environment, from the peaks of mountains to the depths of deep-sea hydrothermal vents, and from polar ice caps to tropical rain forests. Biodiversity is not only the richness of species; it is also their genetic variety and the multiple habitats and ecosystems in which these plants and animals live. Ecosystems contain both the living plants and animals and the nonliving elements (water, sunlight, soils) on which they depend.
\end{abstract}

\section{Keywords}

Aquatic, Biodiversity, Diversity, Fauna, Flora, Marine

$\square$ Sunil Kumar, Email: sunilkumarddn@yahoo.co.in ( ${ }^{*}$ Corresponding author) 


\section{Introduction}

Aquatic biodiversity can be defined as the variety of life and the ecosystems that make up the fresh water, tidal, and marine regions of the world and their interactions. Biodiversity is the variety of life on Earth, it includes all organisms, species, and populations; the genetic variation among these; and their complex assemblages of communities and ecosystems. Biodiversity is the varied and differences among living organisms of terrestrial, marine and other aquatic ecosystems and the ecological complexes associated with them. It includes genetic diversity within and between species of ecosystems (Jena and Gopalkrishnan, 2012). It encompasses diversity at three levels: Genetic diversity-genetic variability within a species; Species diversity- variety of species within community; Ecosystem diversity-the organization of species in an area into distinctive plant and animal communities. Biodiversity is not only the richness of species, it is also their genetic variety and the multiple habitats and ecosystems in which these plants and animals lives. The study of biodiversity on both global and regional scales come mainly from the terrestrial environment despite the marked distinctive features of marine biodiversity and the fact that the aquatic (freshwater and marine) environment occupies more than two thirds of the Earth's surface. Each species is adopted its unique niche in the environment, from the peak of mountains to depth of deep ocean, and from polar ice caps to tropical rain forest (Tiwari and Bisht, 1991). Aquatic biodiversity is the rich and wonderful variety of plant and animals. It consists of phytoplankton, zooplankton, aquatic plants, insects, fishes, birds, mammals and others. Many species of animals and plants live in water; some, like fish, spend all their live underwater, whereas others, like toads and salamanders, may use surface waters only during the spring breeding season or as juveniles. Some aquatic creatures live their entire lives in the deep ocean, whereas others, like water striders, spend their life skipping along the surface of water (Chandra et al. 2017).

Biological biodiversity is the variability among living organisms from all sources including terrestrial, marine and other aquatic ecosystem and the ecological complexes. An ecosystem contains both biotic and abiotic components. Aquatic ecosystem includes our rivers and streams, ponds and lakes, oceans and bays, and swamps and marshes and their associates. As with terrestrial ecosystems, aquatic biodiversity varies from region to region. Aquatic biodiversity is greatest in tropical latitudes. About 22000 species of fishes have been recorded in the world; of which, about $11 \%$ are found in Indian waters. Out of the 2200 species so far listed, 73 (3.32\%) belong to the cold freshwater regime, 544 $(24.73 \%)$ to the warm fresh waters domain, $143(6.50 \%)$ to the brackish waters and $1440(65.45 \%)$ to the marine ecosystem (Venketraman and Raghunathan, 2015). Adequate protection of ecosystems is a necessary requirement for survival of all species and proper care is needed to overcome anthropogenic stresses. In the case of commercial species, rational exploitation is a pre- requisite for sustainability of the resources. There are about 450 families of freshwater fishes globally. Roughly 40 are represented in India (warm freshwater species). About 25 of these families contain commercially important species. Coral reef habitats also have extremely high biodiversity; nearly a quarter of all known marine species are found in coral reefs. The Great Barrier Reef, off the coast of Australia, is the largest coral reef system 
in the world. It supports over 700 species of coral, in addition to 1,600 fish species and 4,000 species of mollusks. Over 1.4 million identified species live on earth, and experts estimate that as many as another 10 million to 100 million unidentified species may exist (Joshi et al., 2015).

\section{Fresh water biodiversity}

Freshwater ecosystems are a subset of Earth's aquatic ecosystems. They include lakes, ponds, rivers, streams, springs, bogs, and wetlands. Limnology (a branch of freshwater biology) is a study about freshwater ecosystems. It is a part of hydrobiology. Freshwater habitats can be classified by different factors, including temperature, light penetration, nutrients, and vegetation (Robert, 2001). Temperature in fresh water habitats does not show much range of variation, due to several unique thermal properties of water. Turbidity of water depends upon the kinds and amount of suspended material like silt, clay particle and living organism etc. Turbidity affects the penetration of light and thus is important factor in the distribution of organisms. Large rivers have comparatively more species than small streams. Many relate this pattern to the greater area and volume of larger systems, as well as an increase in habitat diversity. Some systems, however, show a poor fit between system size and species richness. Organisms in fresh water habitats are generally classified in to following manner: on the bases of their major niches, their life habit and sub habitat they are autotrophs (producers), phagotrophs (macroconsumers), saprotrophs (decomposer or microconsumer), benthos (bottom), periphyton (attached to other plants), planktons (floating), nekton (swimming) and neuston (resting or swimming on surface). Freshwater ecosystems can be divided into lentic ecosystems (still water) and lotic ecosystems (flowing water).

The earliest vertebrates appeared in the form of fish, which live exclusively in water. Tiny fish may be ancestor of nearly all living vertebrates (Live Science, 2014). Some of these evolved into amphibians which spend portions of their lives in water and portions on land. Other fish evolved into land mammals and subsequently returned to the ocean as seals, dolphins or whales. Plant forms such as kelp and algae grow in the water and are the basis for some underwater ecosystems. Plankton and particularly phytoplankton are key primary producers forming the general foundation of the ocean food chain. Fresh-water habitats are threatened by many factors, including pollution from industry, increased acidification, and agricultural runoff containing residues of fertilizers or pesticides. In addition, the building of dams destroys many river ecosystems. Development can harm aquatic habitats or remove them altogether, as when marshy areas are filled. In the 20th century, the basis of intensive studies on the different families and groups of freshwater fishes was done by Chaudhuri along with Hora and his co-workers. Misra (1976) published An Aid to Identification of the Commercial Fishes of India and Pakistan and The Fauna of India and Adjacent Countries. Jones and Kumaran described about 60 species of fishes in the work Fishes of Laccadive Archipelago. The FAO Species Identification Sheets for Fishery Purposes - Western Indian Ocean (Fischer and Bianchi) is still a valuable guide for researchers. 


\section{Lentic communities}

Lentic communities are found in three distinct zone i.e., littoral, limnetic and profundal. Producers like, rooted and benthic plants (Nymphaea, Nelumbo), mainly seed plants, rooted hydrophytes (Typha, Scirpus, sagittaria, Eleocharis etc.), floating green plants, the phytoplanktons, mainly the algae are distributed in these zones. These algae are diatoms, green algae, including unicellular forms as desmid, filamentous (attached or floating) as species of Spirogyra, Oedogonium, Cladophora, Chara etc., and various colonial forms as Volvox, Hydrodictylon etc.; blue green algae, which are unicellular and colonial. In littoral zone the consumer is animal in which vertical rather than horizontal zonation is more striking. The zooplankton represents a few species but their number is large. Copepods, cladocerans and rotifers are chiefly present. Common forms are other vertebrate taxa inhabit lentic systems as well. These include amphibians (e.g. salamanders and frogs), reptiles (e.g. snakes, turtles, and alligators), and a large number of waterfowl species (Moss, 1998). Many fish species are important as consumers and as prey species to the larger vertebrates mentioned above Fish size, mobility, and sensory capabilities allow them to exploit a broad prey base, covering multiple zonation regions. Like invertebrates, fish feeding habits can be categorized into guilds. In the pelagic zone, herbivores graze on periphyton and macrophytes or pick phytoplankton out of the water column. Carnivores include fishes that feed on zooplankton in the water column (zooplanktivores), insects at the water's surface, on benthic structures, or in the sediment (insectivores), and those that feed on other fish (piscivores). Fish that consume detritus and gain energy by processing its organic material are called detritivores. Omnivores ingest a wide variety of prey, encompassing floral, faunal, and detrital material. Finally, members of the parasitic guild acquire nutrition from a host species, usually another fish or large vertebrate (Poff et al., 2006). Fish taxa are flexible in their feeding roles, varying their diets with environmental conditions and prey availability. Many species also undergo a diet shift as they develop. Therefore, it is likely that any single fish occupies multiple feeding guilds within its lifetime (Lytle, 1999).

\section{Lotic communities}

Lotic systems typically connect to each other, forming a path to the ocean (spring $\rightarrow$ stream $\rightarrow$ river $\rightarrow$ ocean). Up to $90 \%$ of invertebrates in some lotic systems are insects. These species exhibit tremendous diversity and can be found occupying almost every available habitat, including the surfaces of stones, deep below the substratum, and in the surface film. Invertebrates are important as both consumers and prey items in lotic systems. Insects have developed several strategies for living in the diverse flows of lotic systems. Some avoid high current areas, inhabiting the substratum or the sheltered side of rock (LeRoy et al., 2006). In addition to these behaviors and body shapes, insects have different life history adaptations to cope with the naturally-occurring physical harshness of stream environments (Lytle $e t$ al., 2004). The common orders of insects that are found in river ecosystems include Ephemeroptera (also known as a mayfly), Trichoptera (also known as a caddisfly), Plecoptera (also known as a stonefly, Diptera (also known as a true fly), some types of Coleoptera (also known as a beetle), Odonata (the group that includes the dragonfly and the damselfly), and some types of Hemiptera (also known as 
true bugs). Additional invertebrate taxa common to flowing waters include mollusks such as snails, limpets, clams, mussels, as well as crustaceans like crayfish, amphipoda and crabs.

Fish are probably the best-known inhabitants of lotic systems. The ability of a fish species to live in flowing waters depends upon the speed at which it can swim and the duration that its speed can be maintained. Continuous swimming expends a tremendous amount of energy and, therefore, fishes spend only short periods in full current. Instead, individuals remain close to the bottom or the banks, behind obstacles, and sheltered from the current, swimming in the current only to feed or change locations. Some species have adapted to living only on the system bottom, never venturing into the open water flow. These fishes are dorso-ventrally flattened to reduce flow resistance and often have eyes on top of their heads to observe what is happening above them. Some also have sensory barrels positioned under the head to assist in the testing of substratum. Other vertebrate taxa that inhabit lotic systems include amphibians, such as salamanders, reptiles (e.g. snakes, turtles, crocodiles and alligators) various bird species, and mammals (e.g., otters, beavers, hippos, and river dolphins). Other vertebrate taxa that inhabit lotic systems include amphibians, such as salamanders, reptiles (e.g. snakes, turtles, crocodiles and alligators) various bird species, and mammals (e.g., otters, beavers, hippos, and river dolphins). With the exception of a few species, these vertebrates are not tied to water as fishes are, and spend part of their time in terrestrial habitats (Giller and Malmqvist, 1998). Many fish species are important as consumers and as prey species to the larger vertebrates mentioned above.

\section{Marine diversity}

Marine ecosystems, the largest of all ecosystems (The Marine Biome, 2018). A large proportion of all life on Earth lives in the ocean. The exact size of this large proportion is unknown, since many ocean species are still to be discovered. The ocean is a complex three-dimensional world covering approximately $71 \%$ of the Earth's surface (Marine Conservation Institute, 2013). They are distinguished from freshwater ecosystems by the presence of dissolved compounds, especially salts, in the water. In its simplest form, biodiversity or biological diversity is therefore 'Life on Earth' and includes marine biodiversity 'Life in the Seas and Oceans. The marine environment has a very high biodiversity because 32 out of the 33 described animals phyla are represented in there (MarBEF's, 2009). A greater variety of species at a higher tropic level are exploited in the sea than on land. Marine life, or sea life or ocean life, is the plants, animals and other organisms that live in the salt water of the sea or ocean, or the brackish water of coastal estuaries. At a fundamental level, marine life affects the nature of the planet. Marine organisms produce oxygen. Shorelines are in part shaped and protected by marine life, and some marine organisms even help create new land. Marine diversity totally depends upon the pattern or the relationship between organism and the sea environment. Exploitation of marine biodiversity is also far less managed than on land (Heip et al., 1998, Giller et al., 2004). Environmental change in the sea has a much lower frequency than on land, both temporally and spatially. Marine organisms play crucial roles in many bio-geochemical processes that sustain the biosphere, and provide a variety of products and 
functions which are essential to mankind's well-being, including the production of food and natural substances.

Marine systems are more open than terrestrial and dispersal of species may occur over much broader ranges than on land (Heip et al.. 1998). The main marine primary producers are very small and often mobile, whereas on land primary producers are large and static. The standing stock of grazers is higher than that of primary producers in the sea, the reverse of the situation on land. In the largest part of the ocean, beneath the shallow surface layers, no photosynthesis occurs at all (Heip et al., 1998, Giller et al., 2004). In addition, pollution from the air, land and freshwater ultimately enters the sea and therefore marine biodiversity is most exposed to, and critically influences the fate of, pollutants in the world (Heip et al., 1998). Marine ecosystems can be divided into many zones depending upon water depth and shoreline features. The shallow water zone on the continental shelf is the Neritic zone, can include estuaries, salt marshes, coral reefs, lagoons and mangrove swamps. The zone between high and low tides is known as the Intertidal zone. The region of the open sea beyond the continental shelf is called Oceanic region, which comprises the region of continental slop and rise- the Bathyal zone; area of the ocean deeps- Abyssal region; and light compensation zone separating an upper thin Euphotic zone from a vastly thicker Aphotic zone (Figure 1) (Kirsten et al., 2017).

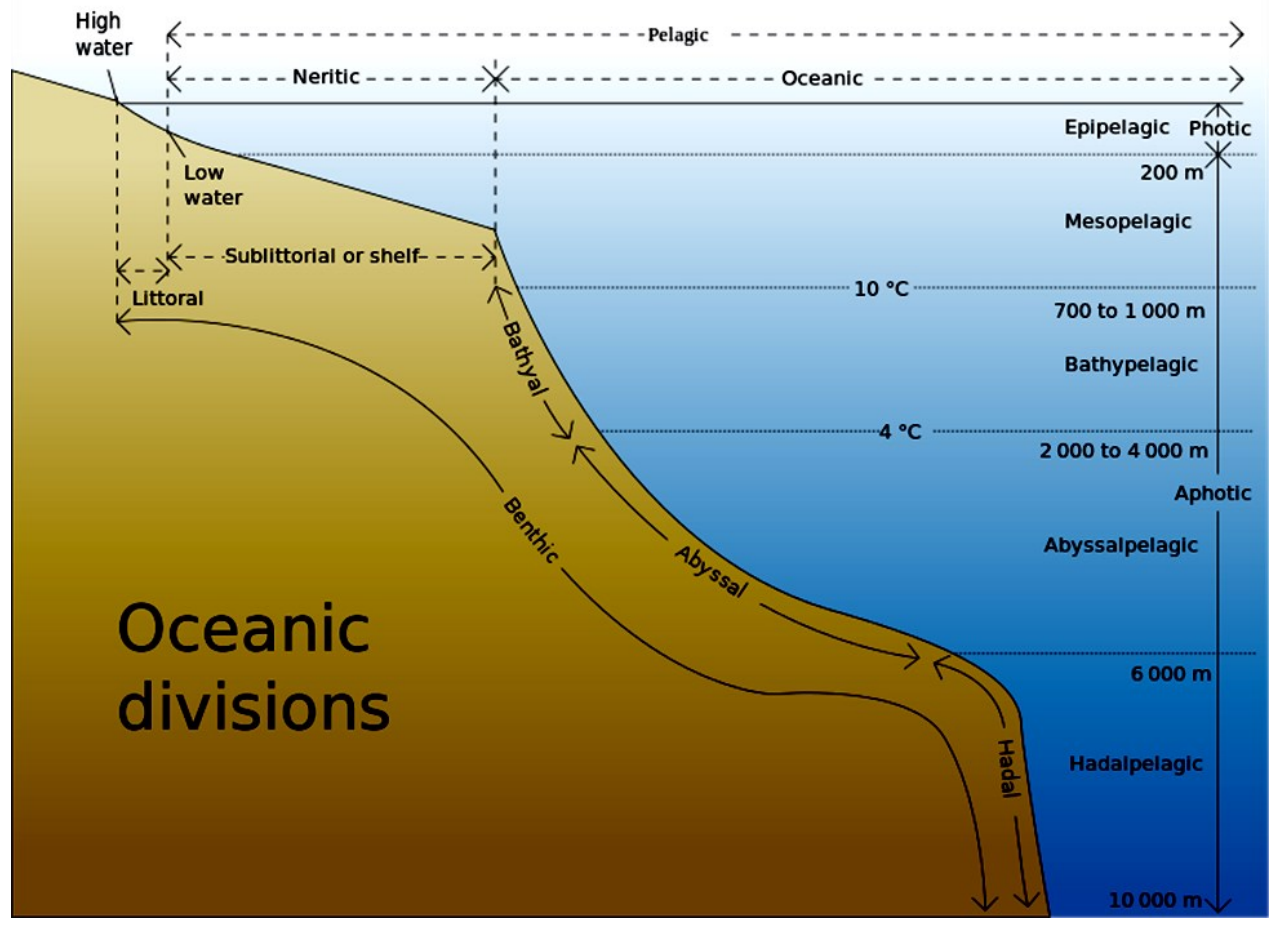

Figure 1. Division of oceanic zones (Adopted from: Kirsten et al., 2017). 
The organisms of marine environment show great diversity in their form, and it becomes difficult to list. Marine invertebrates are the invertebrates that live in marine habitats. Invertebrate is a blanket term that includes all animals apart from the vertebrate members of the chordate phylum. Invertebrates lack a vertebral column, and some have evolved a shell or a hard exoskeleton. As on land and in the air, marine invertebrates have a large variety of body plans, and have been categorised into over 30 phyla. They make up most of the macroscopic life in the oceans. The earliest animals were marine invertebrates, that is, vertebrates came later. Animals are multicellular eukaryotes and are distinguished from plants, algae, and fungi by lacking cell walls (Davidson et al., 2005). Marine invertebrates are animals that inhabit a marine environment apart from the vertebrate members of the chordate phylum; invertebrates lack a vertebral column. Some have evolved a shell or a hard exoskeleton. Invertebrates are grouped into different phyla. Informally phyla can be thought of as a way of grouping organisms according to their body plan (Valentine et al., 2004). A body plan refers to a blueprint which describes the shape or morphology of an organism, such as its symmetry, segmentation and the disposition of its appendages. Coelenterates, sponges, echinoderms, annelids e.t.c. that are absent or poorly represented in freshwater are very important in marine water. Insects are generally absent, and the crustaceans constitute the so called "Insect of the sea" (Venkataraman and Raghunathan, 2015). Most life forms evolved initially in marine habitats. By volume, oceans provide about 90 percent of the living space on the planet (Chandra, 2018). Marine invertebrates exhibit a wide range of modifications to survive in poorly oxygenated waters, including breathing tubes as in Mollusca siphons. A reported 33,400 species of fish, including bony and cartilaginous fish, had been described by 2016, more than all other vertebrates combined. About $60 \%$ of fish species live in saltwater (Moyle and Leidy, 1992). Fish have gills instead of lungs, although some species of fish, such as the lungfish, have both. Marine mammals, such as dolphins, whales, otters, and seals need to surface periodically to breathe air. A total of 230,000 documented marine species exist, including about 20,000 species of marine fish, with some two million marine species yet to be documented (Bob, 2009). Reptiles which inhabit or frequent the sea include sea turtles, sea snakes, terrapins, the marine iguana, and the saltwater crocodile. Most extant marine reptiles, except for some sea snakes, are oviparous and need to return to land to lay their eggs. Thus most species, excepting sea turtles, spend most of their lives on or near land rather than in the ocean. Despite their marine adaptations, most sea snakes prefer shallow waters nearby land, around islands, especially waters that are somewhat sheltered, as well as near estuaries. (Stidworthy, 1974; Sea snakes at Food and Agriculture Organization of the United Nations, 2007). Some extinct marine reptiles, such as ichthyosaurs, evolved to be viviparous and had no requirement to return to land. Marine species range in size from the microscopic, including plankton and phytoplankton which can be as small as 0.02 micrometers, to huge cetaceans (whales, dolphins and porpoises), including the blue whale - the largest known animal reaching up to 33 meters (108 ft) in length (Paul, 2010; Bortolotti, 2008). Marine microorganisms, including bacteria and viruses, constitute about $70 \%$ of the total marine biomass, National Oceanic and Atmospheric Administration - Ocean" (NOAA, 2019). 


\section{Conclusion and recommendations}

India has great diversity in its Geo-climatic conditions. Biodiversity is the varied and differences among living organisms of terrestrial, marine and other aquatic ecosystems and the ecological complexes associated with them. India has great diversity in its geo-climatic conditions. Thus, there is great diversity in India's forest, wetlands, mangroves wildlife and marine areas. The richness in fauna and flora makes it as one of the 12 mega-biodiversity countries of the world. Aquatic ecosystems also are particularly fragile because the disturbance of a watershed can affect multiple components downstream, including rivers, lakes, estuaries, and oceans. Freshwater habitats can be classified by different factors, including temperature, light penetration, nutrients, and vegetation perhaps the largest threat to ocean biodiversity is overfishing. In addition to depleting commercial species of fish, bivalves, and crustaceans, many fishing methods cause the needless deaths of noncommercial fish species as well as numerous reptiles, birds, and marine mammals (Tiwari and Bisht, 1991). The long coastline of 8129 $\mathrm{km} 2$ with an EE2 of 2.02 million sq. $\mathrm{km}$ including the continental shelf of 0.5 million sq. $\mathrm{km}$ harbors extensively rich multitude of species. Vast regions of mangroves are found along the coast of West Bengal, Orissa, Andhra Pradesh, Tamilnadu, Maharashtra, Gujarat and Andaman Islands which extends up to about 6,82,000 ha area. Coral reefs are found in the Gulf of Kutch, along the Maharashtra coast, Kerala coast, in the Gulf of Mannar, Palk Bay and the Wedge Bank along the Tamil Nadu coast and around Andaman and Lakshadweep Islands. The variety of coastal ecosystems includes brackish water lakes, lagoons, estuaries, back waters, salt marshes, rocky bottom, sandy bottom and muddy areas provides a home and shelter for the mega biodiversity of India (Sahil, 2018). These regions support very rich fauna and flora and constitute rich biological diversity of marine ecosystems. Diversity in the species complex, typical of tropical waters and co-existence of different fish and shellfish species in the same ground are important features of Indian Marine Biodiversity (Mishra et al., 2017). The diversity in terrain, topography, climate and soils are able to sustain diverse forms of life. Thus, there is great diversity in India's forest, wetlands, mangrove wildlife and marine areas. The richness in fauna and flora makes it as one of the 12 mega-biodiversity countries of the world.

\section{Acknowledgement}

Authors are thankful to Management and Principal, D.A.V. (P.G.) College, Dehradun and Krishna College of science and I.T. Bijnor, for their co-operation and providing infrastructural facility.

\section{References}

Alexander, D.E, (1999), Encyclopedia of Environmental Science. Springer. Bortolotti, D. (2008). Wild Blue, A Natural History of the World's Largest Animal. St. Martin's Press.

Chandra, K., Gopi, K.C., Rao D.V., Subhramanian K.A. and Valarmathi, K. (2017) Current status of fresh water faunal diversity of India- An overview. J.R.B. Alfred Z.S.I. 
Bob, D. (2009). Mapping an ocean of species. Los Angeles Times.

Davidson, M.W. (2005). Animal Cell Structure. Molecular Expressions. Tallahassee, FL: Florida State University,.

Giller, S. and Malmqvist, B. (2019), The Biology of Streams and Rivers. Oxford University Press.

Jena J. K. and Gopalkrishnan A. (2012). Aquatic biodiversity management of India. Proceedings of the National Academy of Sciences India Section B Biological Science, 1-10.

Joshi K.K., Varsha M.S. and Sruthi V.L. (2015). Marine biodiversity of India Status and Challenges. Central Marine Research Institute, Kochi.

Joshi, K.K., Sethulakshmi, M. and Varsha M.S. (2017). Fish biodiversity of Indian exclusive economic zone, Marine Biodiversity Division" ICAR-Central Marine Fisheries Research Institute.

Kaschner K., Tittensor D.P., Ready J., Gerrodette T. and Worm B. (2011). Current and Future Patterns of Global Marine Mammal Biodiversity. PLoS ONE, 6(5): 19653.

Lytle, D.A. (1999). Use of Rainfall Cues by Abedus herberti (Hemiptera: Belostomatidae): A Mechanism. _London. Oceanographic and Bathymetric Features Marine Conservation Institute, pp. 557.

Lytle, D.A., Poff, N. and LeRoy (2004). Adaptation to natural flow regimes. Trends in Ecology and Evolution, 19(2): 94-100.

MarBEF's (2009). Marine Biodiversity and Ecosystem Functionin.

Moss, B. (2013). Ecology of Freshwaters: man and medium, past to future. Blackwell Science.

Moyle, P.B., Leidy, R.A. Fiedler, P.L. and Jain, S.A. (1999). Loss of biodiversity in aquatic ecosystems: Evidence from fish faunas". Conservation Biology: the theory and practice of nature conservation, preservation, and management. Chapman and Hall, pp 128-169.

Naqutiyal P., Mishra A.S., Singh K.S. and Singh U. (2013). Longitudinal Distribution of Fish Fauna in the river Ganga from Gangotri to Kanpur. Journal of Applied and Natural Science, 5(1): 63-68.

National Oceanic and Atmospheric Administration (2019). Ocean. NOAA.

Poff, N. and LeRoy (2006). Functional trait niches of North American lotic insects: traits-based ecological applications in light of phylogenetic relationships. Journal of the North American Benthological Society, 25(4): 730-755.

Paul, G.S. (2010). The Evolution of Dinosaurs and their World". The Princeton Field Guide to Dinosaurs. Princeton: Princeton University Press.

Stidworthy J. (1974). Sea snakes at Food and Agriculture Organization of the United Nations. Accessed 7 August 2007. Snakes of the World. Grosset \& Dunlap Inc. pp. 160.

Sahil H. (2018). Marine Biodiversity in India with special reference to conservation, status and issue. 3rd International Conference on Costal Zones and Oceanography.

Tewari, G. and Bisht, A. (1991). Aquativ Biodiversity threats and Conservation. In: Aquafinder, pp. 13.

The Marine Biome (2018). University of California Museum of Paleontology, Retrieved on 27 September 2018.

Venkataraman, K. and Raghunathan, C. (2015). Marine faunal biodiversity of India. Costal and marine Biodiversity of India . pp. 303-348.

Valentine, J.W. (2004). On the Origin of Phyla. "Fishbase". Retrieved 6 February 2017.

Wetzel, R. (2001). Limnology: lake and river ecosystems (3rd ed.). San Diego: Academic Press, pp. 44.

$* * * * *$

Cite this chapter as: Kumar, S. and Devi, S. (2021). An overview on aquatic biodiversity of India. In: Biological Diversity: Current Status and Conservation Policies, Volume 1, Eds. Kumar., V., Kumar, S., Kamboj, N., Payum, T., Kumar, P. and Kumari, S. pp. 158-166, https://doi.org/10.26832/aesa2021-bdcp-010 